\title{
Human Capital as One of the Drivers of Reliable Value of Medical Entities on the Example of International Cardiac Hospital
}

\author{
Hanna Kociemska \\ Finance Faculty, University of Economics in Wroclaw, Wroclaw, Poland
}

Email address:

hanna.kociemska@ue.wroc.pl

\section{To cite this article:}

Author. Human Capital as One of the Drivers of Reliable Value of Medical Entities on the Example of International Cardiac Hospital. International Journal of Economics, Finance and Management Sciences. Vol. 4, No. 2, 2016, pp. 78-82. doi: 10.11648/j.ijefm.20160402.16

Received: January 1, 2016; Accepted: January 20, 2016; Published: March 18, 2016

\begin{abstract}
This paper constitutes a contribution to a new discussion on the adequacy of existing company valuation methods with regard to the specific nature of medical entities in Poland. The research method used to fulfil the given scientific aims are: monographic methods, literature research on theory of company valuation, research survey on particular medical entity and its business performance results, statistical quantitative and qualitative analysis, case study analysis. The author points out the shortcomings of existing theories. Calls for taking into account the quality of the activities performed by medical companies in the methodology used for their valuation. As the outcome it is underlined that the human capital at the hospital is one of the key indicators of quality of their activity, translating into the value the entity has for its owner. Thus the scientific conclusion will be that better quality the medical personnel was the better financial ratios were achieved but it doesn't find it's reflection in existing company valuation method. Specially in case of medical entities human capital value seems to be crucial according to the business. It is being shown on cardiac hospital example. It should be evaluated on existing theories and looked for more sophisticated valuation method adjustable for health care entities not only in Poland but worldwide.
\end{abstract}

Keywords: Human Capital, Value of Medical Entity, Mmedical Market, Hospital Market Transformation

\section{Introduction}

Contribution to the determination of the value of polish medical enterprises. Their financial standing and transformation-related plans.

The aim of this paper is to start a wider discussion about the usefulness of the enterprise valuation methods applied to perform valuation of medical enterprises. The author points out hypothesis that specific value drivers need to be taken into account in the company valuation methodology which may prove key for the valuation of medical enterprises. The idea of valuation of such entities is becoming increasingly relevant in Poland. The legislative activities in course related to health care aim at broad ownership restructuring processes in the industry. They will therefore inevitably require information to be used concerning the value of the transformed enterprise: such information will then constitute the "accounting" basis for establishing the new transformed entity. Transformation of the medical market is also a global process. The research findings obtained may therefore prove useful for medical market participants in most developing countries where the processes of establishing international medical company networks are becoming increasingly popular.

Among the research method is monographic method, based on a detailed study of a specific (individual) case, that is a statistical unit constituted by particular private cardiac hospital under research. By applying this method qualitative and descriptive information is primarily taken into account. Author applied also the method of analysis and critique of scientific literature with respect to company valuation methods with regard to the specific nature of medical entities in Poland. The above will be summarized by the application of the method of analysis and logical structure through which the researcher synthesize previously obtained results. This will allow for verification of a hypothesis and the formulation of general scientific claims expanding existing theories in the study of medical company valuation process. 
When analysing information on the level of debt of public medical entities in Poland, the following premises should be indicated related to the implementation of processes to transform the health care services market from the point of view of the founding bodies that manage such entities:

a) legislative mechanisms, provisions of the act on health care activity, assuming aid to commercialised entities; remission of some payables; targeted subsidies for the repayment of payables taken over; solutions forcing founding bodies to potentially cover a negative financial result of the public medical entity using their own funds unless the transformation process is implemented [Horosz...2011, 3];

b) financial mechanisms: impossibility of financing development, but also the on-going activity of the public medical entity due to the overly high level of debt of the founding bodies; impossibility of incurring further financial obligations to ensure the performance of the statutory functions of providing society with a suitable quantity and quality of medical services;

c) management mechanisms: impossibility of improving management standards at public medical entities due to the scarce possibility of sharing knowledge and experience or extending knowledge among managers whose activity is also disrupted by the political factor, i.e. the fact that management-related decisions survive political terms of office.

Intensified ownership changes may therefore be expected in the area of non-public medical entities which will seek to become partners in the transformation processes, as the transformation on the public hospital market progresses, or to participate in the processes of consolidation of medical entities taking place in Poland. Public-private partnership may also become an increasingly accepted formula of conducting activity and implementing investments. Valuation of individual entities participating in such processes is key for the performance of further activities by the public-private entity. Such valuation constitutes the basis for the relationship linking the public and the private entity, translating into the value of shares taken up for the publicprivate company constituting the special purpose vehicle. Public private partnership is becoming a solution used increasingly often in transformation processes on medical services markets in the whole world. Consequently, the idea of value drivers for medical entities may prove useful for participants of markets in the process of globalisation.

\section{Standard Enterprise Valuation Methods}

Standard enterprise valuation processes most often use asset-based methods, income-based methods and the discounted cash flow method. It is more often discussed where the existing methods are accurate or how to modify to enable the owners smooth transition through valuation process. One of the basic research was conducted by R. J.
Cimasi [Cimasi ...2014, 1]. He underlined that healthcare valuation has emerged into a specialized field, requiring background, discernment and work experience in order to be effective. Healthcare business is constantly changing and its valuation requires consideration of both: nuances created by industry practice and by regulations

Summing it up: enterprise valuation methods [Koller ... 2010, 4]:

1) asset-based methods: they consist in the estimating of the value of assets, i.e. the total labour inputs, money and tangible assets used to establish the enterprise. Such methods include accounting valuation, the adjusted net assets method, the liquidation value method, the replacement value method and the liquidation method;

2) income-based methods involve estimating income value perceived as the sum of income that can be obtained while operating the enterprise within a specific time frame. This group includes mainly discounted profit, discounted cash flow and discounted dividend models;

3) market comparison-based methods: the market value is estimated, i.e. the hypothetical transaction price the owner may potentially obtain in the selling process. The following principal ratios are used here for the purposes of comparison: price / profit; price / sales; price / EBITDA; dividend / share; price / book value;

4) mixed methods: the resultant is used here (simple or weighted arithmetic mean) of the values obtained in asset-based, income-based and market valuations [Pantafil...2009, 7].

In author's opinion resulting from both research outcomes and business experiences the definitions presented above do not make it possible, however, to present the effective value of health care entities in Poland. The following arguments confirm above hypothesis, for instance:

- there are many medical entities that have very little tangible property and often tangible fixed assets whose value equals zero or which are not owned by the hospital, but rather by third parties;

- as a matter of principle, public medical entities are not income-oriented [12], since the basic and only entity paying for the service, i.e. the National Health Fund (NFZ), finances them exclusively at the level of basic costs of medical procedures, not taking into account other costs of activity or the expected profitability of the medical service;

- no transactions have taken place on the market so far consisting in the purchase and sale of public medical entities, which makes it impossible to apply the comparative transactional methodology of company valuation.

\section{Discussion Specific Value Drivers for Medical Enterprises in Poland, Including Human Capital}

In the author's opinion, the following constitute key 
additional value drivers for medical entities that could be taken into account apart from standard enterprise value metrics:

- "human capital" of the medical entity,

- correctly defined profile of the medical entity, justified by demographic and epidemiological analyses in the entity's location, ensuring justified operation in a longer period,

- the referral level of the medical entity, including up-todate medical technology used there.

The second value driver of those indicated above for medical entities is a correctly defined profile of the medical entity, justified by demographic and epidemiological analyses in the entity's location. This aspect is particularly important when an income-based method of enterprise valuation is used. Due to the lack of nationwide monitoring of patients' needs with regard to medical care in Poland, no institution is responsible for, monitors or points to the justification of performing medical activity in a specific medical area. The risk thus lies entirely with the medical entity's owner. It consists in the mismatch between the profile of activity and the actual needs of the community in the relevant region. It may turn out, in fact, that when the operating base and number of available beds are not monitored, too many medical entities will be established offering the same services, or new medical entities will be established whose profile will not correspond to the local community's needs.

Another significant element in the determination of the value of medical entities should be the entities' referral level. In Poland, the referral level attributed for instance to cardiac wards depends on the medical equipment available at the relevant centre and on qualified staff achieving outstanding research results there. According to the Ministry of Health, "Referral level is determined by professional preparation and education of the working staff and by the equipment available at the relevant centre." The cardiac wards in Poland (in the total number of 37 clinics (1026 cardiac beds), are operated more then 26000 heart operations annually have the referral levels from grade I till grade III, but none of them is based on the medical results obtain in given period [11].

The author, however, wishes to focus on human capital as one of the additional value drivers for medical entities. Intellectual capital constitutes increasingly often a significant value for the entire enterprise [Lindsey...Moore, 2008, 14]. This is proven by the constant widening of the gap between the market value and the book value of the enterprise and by the fact that intellectual capital may account for about a dozen to more than $100 \%$ of the market value of the enterprise [Pantafil...2009, p179]. Tobin's Q ratio, calculated intangible value (CIV) and income from knowledge capital are used in the intellectual capital valuation methodology applied [Moshe...6]. The intellectual capital of the medical entity's employees definitely has a specific value. Intellectual capital as human capital at a hospital corresponds to all the employees responsible for the correct organisational and medical functioning of the hospital. This aspect is a significant asset of any medical unit, since the possibility of rendering services and their quality certainly depends on the availability and quality of the human resources working at the hospital [Yeh You Lin...2004, 9]. As far as medical entities are concerned, their success on the market depends increasingly on their market value and position with regard to the competitors. Medical entities must therefore get used to the fact that their key capital may prove to be human capital as the entity's intellectual capital. Few scientific studies have appeared so far in Poland concerning the human capital of medical entities, which would prove that knowledge and awareness of the assumptions of medical entities' operation are lacking [Molesworth..., 5].

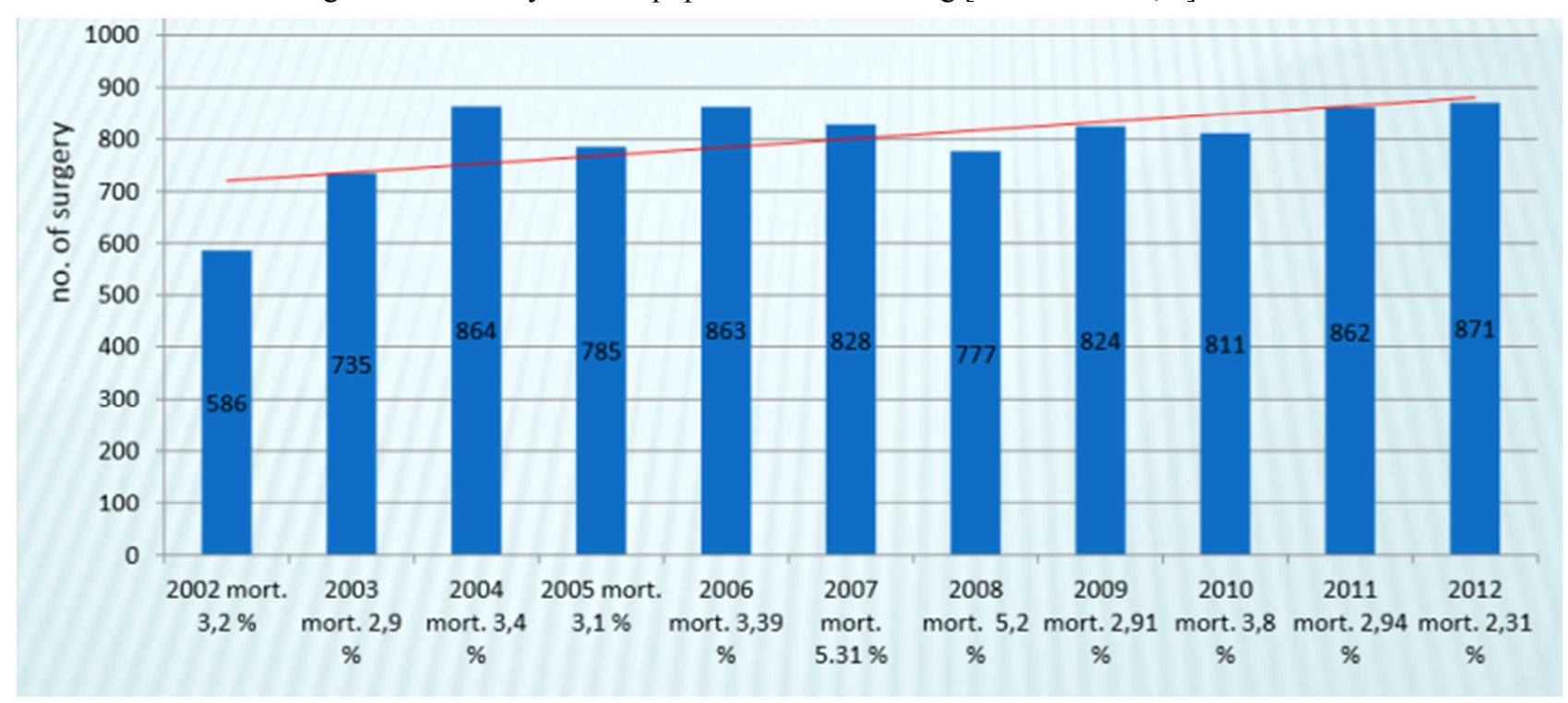

Source: Cardiac Hospital HR department data, own summary¹.

Figure 1. Medical results in particular procedure where highly professional personnel is involved. 
Of particular note, from the point of view of a potential owner that estimates the value of the medicinal entity, deserves quality medical personnel performance. For confirmation of this thesis the author below shows the data of one of the cardiac ward in Poland in past four selected years. On the one hand, they presented data demonstrates activities in selected medical procedure that requires the participation of highly qualified medical staff, as they are high-risk procedure. On the other hand there are shown the financial results of the company. The data confirm that the more experienced and stable medical staff, the better were the results obtained by company. These positive changes in quality (lower mortality rate, constantly growing number of cardiac operations) were not associated with key investments in medical equipment or not at all reflected in the reference level of the analyzed entity (parsed entity has a lower degree than the local referral academic center). From the point of view of a potential purchaser of this entity the medical value of the company in recent years, measured by assets would be stable. There were no renewal of fixed assets, not being a significant investment, not increased significantly the profitability of sales. Meanwhile, indicators of quality of medical activity clearly were improved.

Table 1. Financial outcomes - cardiac ward.

\begin{tabular}{lllll}
\hline In mln PLN & $\mathbf{2 0 0 7}$ & $\mathbf{2 0 0 8}$ & $\mathbf{2 0 0 9}$ & $\mathbf{2 0 1 0}$ \\
\hline Operational revenue & 25,00 & 29,00 & 32,00 & 33,00 \\
Operational costs & 24,00 & 28,00 & 30,00 & 31,00 \\
Other costs & 1,90 & 1,50 & 1,10 & 2,10 \\
EBIT & 0,60 & 1,50 & 1,40 & 0,20 \\
\hline
\end{tabular}

Source: Cardiac hospital financial statements, own summary from company's financial statements.

Increasingly often, however, the reduction in the number of doctors, nurses, paramedics and auxiliary staff constitutes a limitation in terms of ensuring continuity of medical services or their suitable quant [Aluttis, Tewabech...2014, 13] Even the best technologically equipped hospital will not function in an optimum manner, if there is lack of suitably qualified medical staff at all organisational levels of the health care entity. From the hospital owner's point of view, it is insignificant whether the relevant entity is public or private, so it would be important to indicate the value of the medical company resulting from staff availability and quality. Determination of such factors is not a managerial problem. If data are available concerning hospital size and the projected number of procedures/operations adequate to the number of beds, the number of employees required to fulfil the assumed medical plan can be easily indicated. When the optimum staff numbers are indicated, the working mode and the types of positions need to be taken into account. A significant aspect apart from the number of employees is staff stability. The low fluctuation of staff in relation doctors or nurses is increasingly often judged positively. It is in fact assumed that employees who have a permanent relationship with the enterprise identify with it more strongly and pursue the organisation's goals while fulfilling their own ambitions to the full extent. This is particularly important in the case of medical staff where permanent teams of doctors and nurses ensure a stable team management methodology. This also ensures the highest quality of services performed, with a stable team of people who know each other is proof of mutual understanding and of the right match of qualifications and skills related to treating patients and saving lives. Research by the Health System Trust shows that stability of doctors' and nurses' teams and of surgery teams determines the high quality of medical services and the key value of the hospital as such [Couper...2002, 2].

\section{Conclusion}

To recapitulate, the following information could be used to assess the quality of human capital at a hospital:

- the number of doctors in a breakdown by degrees and specialisations as well as years of practical experience and teaching experience;

- the number of nurses and auxiliary employees in a breakdown by qualifications and years of experience;

- managerial qualification of the management board, hospital directors, their periodic assessment by the owners, anonymous periodic assessment by employees;

- quality ratios concerning surgical activity: fatality rates, complications, re-surgery, length of stay at intensive care units, length of stay at in-patient units, etc., payment for performance (the concept of payment for performance used here refers to remuneration for the outcome of work, an additional bonus for a positive result);

- the terms of employment contracts or other contractual agreements with employees, in which case the longer the contractual term, and thus the more stable the collaboration, the higher the importance of that aspect as a factor contributing to the hospital's value,

- methods of establishing regular collaboration with the employees - staff turnover ratio,

- perspectives for medical staff development: existing and future, rate of their use by the staff, plans for development with regard to improving employees' skills.

Particular attention from the point of view of an owner estimating the value of a health care entity should be dedicated to the quality of the activity performed by the medical staff. In order to confirm that hypothesis, the author presents the data related to cardiac surgery ward over the last given years. On the one hand, it shows data concerning medical activity and characterising the medical staff. On the other hand, it shows the financial results of the enterprise [Cardiac Hospital Internal Data from 2005 - 2013]. The data confirm that the more experienced and stable the medical staff was, the better were the medical results achieved by the company (lower mortality rate and bigger number of operations). Such quality improvements were not linked with key medical investments in equipment and were not reflected 
at all in the referral level of the analysed entity. From the point of view of a potential party acquiring the medical entity, the company's value over the given years determined using an asset-based method would be stable, if not in decline. Renewal of tangible fixed assets has not taken place, significant investments have not been implemented, sales profitability has not increased substantially, but actually even decreased. Quality ratios for medical activity, on the other hand, have been clearly improving.

The thesis that can be put forward as a result of the research presented here is that the potential party acquiring a medical entity in Poland should absolutely be guided not only by the book valuation of the company, but also by quality ratios related to the activity the entity performs. One of the key factors, according to the data, includes the results of operations performed and human resources. The quality ratios related to medical activity and staff qualifications constitute practical key factors of the "value" of a medical entity. In further research, the author intends to build econometric models to confirm the research hypotheses empirically. From the point of view of a potential party acquiring a medical entity in Poland, it would therefore be significant to:

- perform valuation of the medical enterprise using at least two methods (it is impossible to use a comparative method),

- examine the results of medical activities over the longest possible period,

- analyse the human capital in place, actually involved in medical activity over the longest possible period.

It may turn out, in fact, that the outlooks, the actual outcome vs. the forecasts and the income of the medical entity will depend not on the entity's projected financial results but on the perspectives the medical staff working there have. Even a hospital with the best financial management will not be able to exist without the best educated and stable staff, whose performance is higher than average.

A common drawback, however, is the lack of public access to data concerning the results of medical activity. Centres with different referral levels may differ significantly in terms of treatment quality. Even those with a high referral level and access to academic centres may prove less attractive in terms of value for the potential investor, because the medical results obtained do not guarantee operation of the centre over a longer period.

\section{References}

[1] Cimasi R. J., Healthcare valuation, 2 volume set, the financial appraisal of enteprises, assets and services, ISBN: 978-1-11883297-4, april 2014,

http://eu.wiley.com/WileyCDA/WileyTitle/productCd1118832973.html.

[2] Couper I. Prof, Jannie Hugo Prof, Management of district hospitals, suggested elements for improvement August 2002, Health Systems Trust, ISBN: 1-919743-68-5, p. 5.

[3] Horosz P., Komercjalizacja szpitali $i$ jej skutki w świetle przepisów polskiego prawa gospodarczego, ABC Wolter Kluwers Business, Warszawa 2011, p. 44.

[4] Koller T., Goedhard M., Wessels D., Valuation University Edition, Measuring and Managing the Value of Companies, McKinsey and Company, 2010.

[5] Molesworth Sue, Rosalyn Beddows, Helen Parker, University of Keely, Staforsshire, Anglia, Self-directed Team Models in Healthcare Settings.

[6] Moshe B. H., Jeffrey L. Callen, the cost of capital, Macaulay's duration and Tobin'sq., The Journal of financial research, Vol. XII, No. 2, 1989.

[7] Pantafil M., A. Szablewski, Metody wyceny spółki perspektywa klienta i inwestora, Poltext Warszawa 2009, p. 37.

[8] Urbanek G., in: M. Pantafi, A. Szablewski op. cit., p. 179.

[9] Carol Yeh-Yun Lin, Process innovation of an open heart surgical team, National Chengchi University, August 2004, conference paper.

[10] What is Their Potential for Adding Value to the Intellectual Capital of Healthcare Organisations, http://community.mis.temple.edu/mis5102sec401/files/2011/0 2/Self-directed-Team-Models-in-healthcare.pdf.

[11] Report National Cardiac Consultant, Ministry of Health, www.mz.gov.pl, September 2012.

[12] http://www.ifac.org/system/files/publications/files/GoodGovernance-in-the-Public-Sector.pdf.

[13] The workforce for health in globalized context - global shortage and international migration, Christoph Aluttis, Tewabech Bishaw, Martina W. Frank, Glob Health Action. 2014; 7: 10.3402/gha.v7.23611. Published online 2014 Feb 13. doi: 10.3402/gha.v7.23611.

[14] Lindsay Moore Dr., Lesley Craig, Intellectual Capital in Enterprise Success, Strategy Revised, John Wiley and Sons, 2008. 